\title{
Process simulation in temperature control system of oil in autogenous grinding mill
}

\author{
Natalia Borisovna Sibirtseva \\ Department of electrical engineering and automatics \\ Belgorod State Technological University named after V.G. \\ Shoukhov \\ BSTU named after V.G. Shoukhov \\ Belgorod, Russia \\ 308012, Kostukov St., 46 \\ natali.sibirtseva@yandex.ru
}

\author{
Alexandr Vladimirovih Belousov \\ Department of electrical engineering and automatics \\ Belgorod State Technological University named after V.G. \\ Shoukhov \\ BSTU named after V.G. Shoukhov \\ Belgorod, Russia \\ 308012, Kostukov St., 46 \\ ntk@intbel.ru
}

\author{
Alexey Sergeevich Soldatenkov \\ Department of electrical engineering and automatics \\ Belgorod State Technological University named after V.G. Shoukhov \\ BSTU named after V.G. Shoukhov \\ Belgorod, Russia \\ 308012, Kostukov St., 46 \\ soldatenkov.as@bstu.ru
}

\begin{abstract}
To ensure smooth operation of grinding equipment, it is necessary to regulate oil parameters of oilpumping stations used for greasing of various mill moving parts including bearings. As a rule, central oiling systems are local positioned machinery not being a part of the automated dispatch control system of grinding operation. However, the pressure quantity in the oiling system is one of the signals which defines the degree of load ratio, for example, of autogenous grinding mills, therefore it is suggested that such system should be included into the automated control system of grinding operation. For the purpose of oiling system functioning and its parameters regulation for load ratio measurement, the article presents numerical calculations of the mathematical model of the oil cooling system and simulation modelling of this system operations. The simulation results have shown that the proposed structure of oil cooling system has high efficiency and sufficiently low response time. As a consequence, the proposed system provides necessary operating temperature of the oiling system of input and output mill bearings and allows one to measure oil pressure to define the load ratio.
\end{abstract}

Keywords - mathematical modelling, automated system, load ratio, oiling system, mill.

\section{INTRODUCTION}

The present-day production of processing raw materials in the finished product represents a sophisticated automated complex of processing equipment. The quality of the final product is defined by engineering process beginning with open cast mines and finishing with grinding and classification. To provide reliability and smooth operation of grinding machinery, up-to-date automated oil-pumping stations are used, the primary task of which is stabilization of bearings operating temperatures, crown pairs, reducing gear, etc. In the case of greasing substance between sliding surfaces, the friction ratio significantly decreases, thus operating conditions of machinery moving parts are considerably better [1].

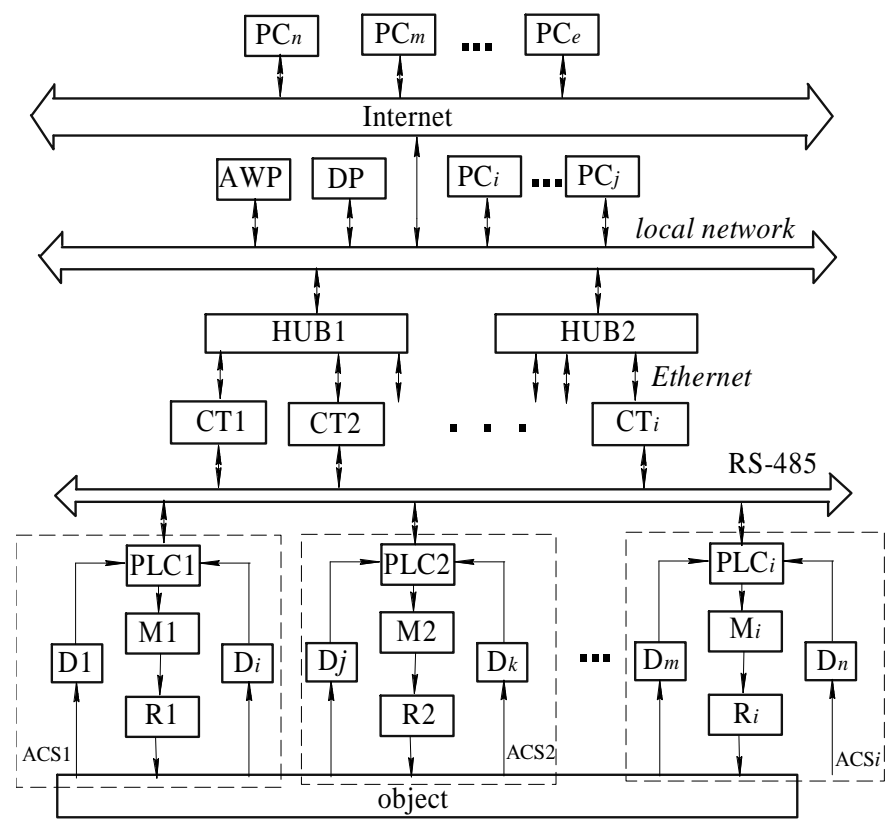

Fig. 1. General flow-chart of automated dispatch control system of grinding operation.

In conjugated components, the lubricant film acts as a hydraulic shock absorber taking up occurring loads. It also protects friction units from corrosion and acting forces 
proceeding from intensive molecular processes as a result of friction $[2,3]$.

The autogenous grinding mills have a relatively simple design and make continuous exploitation with high efficiency possible. To maintain good operational characteristics, it is necessary to keep standard conditions of the oil-pumping station on an on-going basis [4].

For this purpose, local mill oiling automated control systems as other local systems are included as a component of the automated dispatch control system (SCADA) of grinding operation (Fig.1) [5, 6].

The generalized grinding operation of the SCADA-system structure in a form of distributed controlled object includes the following systems and components: local control systems ACS1,.., ACSi with local regulators PLC1,.., PLCi, process parameter sensors $(\mathrm{S} 1, \ldots, \mathrm{Sn})$, actuators $(\mathrm{M} 1, \ldots, \mathrm{Mi})$, control valves $(\mathrm{R} 1, \ldots \mathrm{Ri})$ and others. Besides, SCADA - systems also include mid-tier industrial sequence controls $\mathrm{CT} 1, \ldots \mathrm{CT}$ connected to local regulators $\mathrm{Ri}$ [7].

One of the local low-level SCADA-systems is an automatic control system of greasing mill-sliding surfaces on the basis of centralized oil-pumping stations.

Initial information from the pressure control device located in one of the central oiling systems is necessary for its usage in automated system of mill charge as with the change of load ratio in autogenous grinding mills and other types of raw mills the pressure in oiling system varies. To obtain functional relations between the mill charge and the pressure in hydraulic system pumps of the central oiling system it is necessary to provide stabilization of light oil amount in mill greasing systems, as well as provide compensation of perturbation actions in central oiling systems with account of oil heating and cooling in different periods of a year.

The scheme of mill central oiling system with the use of high-low pumps is shown in Fig. 2.

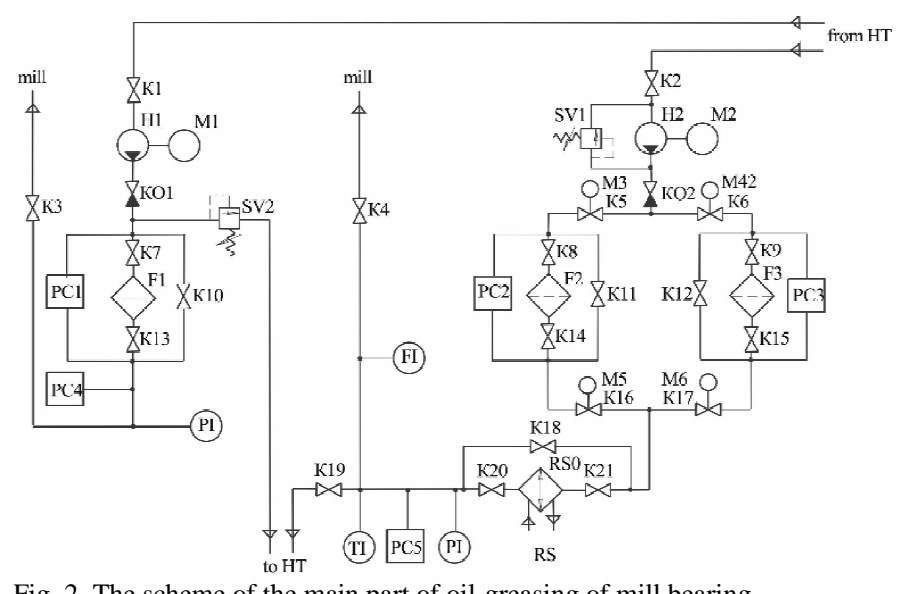

Fig. 2. The scheme of the main part of oil-greasing of mill bearing

In this case the initial information from the pressure control devices in oiling hydraulic systems will be used not only for the purpose of oil greasing functioning but for determining the degree of mill load ratio by raw materials [5, 8]. Notations of bearing oiling system components in the scheme (Fig. 2) are as follows: ball valves K1-K4, K7-K15, $\mathrm{K} 18-\mathrm{K} 21$, motor drives M1 and M2 correspondingly of mill high-pump $\mathrm{H} 1$ and mill low-pump $\mathrm{H} 2$, security valves SV1 and SV2, check valves $\mathrm{KO} 1$ and $\mathrm{KO} 2$, valves $\mathrm{K} 5$, K6, K16, K17 with corresponding electromagnetic drives M3 - M6, oil filters F1-F3, differential pressure switch PC1-PC3, pressure limit switch PC4 and PC5, oil cooler RS0, devices for measurement of, correspondingly, flow rate FI, pressure PI and temperature TI. The additional notations are the following: mill (delivery of oil to the mill bearing), oil box $\mathrm{HB}$ and oiling cooling system communication RS.

The oil temperature in the oiling system is perturbation action, therefore, it is necessary to take into consideration oil heating and cooling in different periods of a year.

The basic controlled parameters of cooling process of mill input bearing with the help of central oiling system with account of the scheme in Fig. 3, are as follows (with account of starting main drive motor operation and with accepted values):

The flow chart of oiling system automation is shown in Fig. 3.

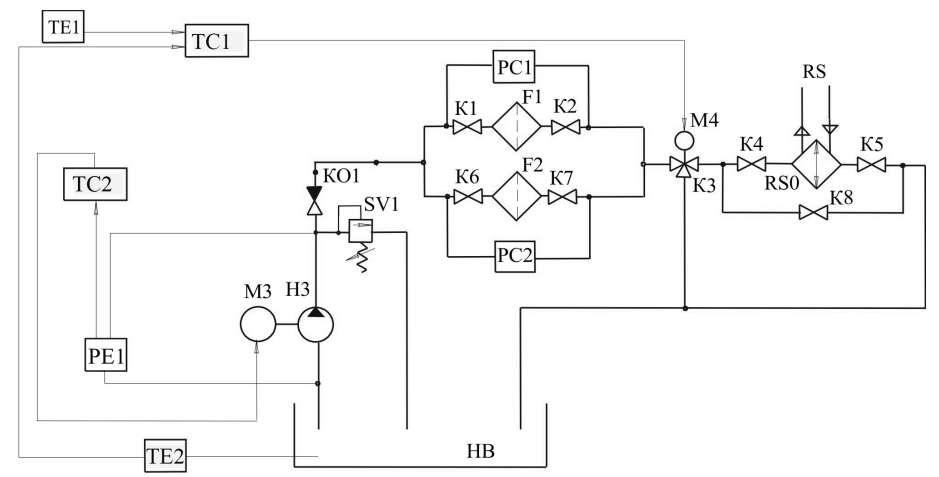

Fig. 3. The flow chart of oiling system automation.

The structure of this system includes the following components: TC1 - local controller for stabilizing oil lubrication temperature; TE3 - environment temperature detector; TE2 - oil temperature sensing unit after the oil cooler; TE1 - oil temperature sensing unit in the oil cooler input; TC2 - local controller for drive motor pump control; PE1 - differential pressure transmitter; M3 - drive motor of low-pump H3; M1 - actuator of the three-way regulatory division valve $\mathrm{K} 1$; RS - cooling system. Besides, there are some hydraulic elements in the system, and namely, F1 and F2 - oil filters; PC1 and PC2 - pressure difference switches, K2K8 - ball valves, SV1 - security valves.

The temperature control of oil lubrication is carried out by change of oil lubrication flow rate through the oil cooler RSO. The controlled variable of the local control system is an oil lubrication temperature after oil cooling, and actuating variable is a flow rate of oil lubrication through the oil cooler.

The local system of automatic control provides the cooling process of oil lubrication on the basis of controller TC1. If the temperature of oil lubrication of oil box is within the range of less than maximum and more than minimal, the hydraulic 
system of oil lubrication functions within a specified schedule and the output signal in the controller TC1 output is absent.

When the oil lubrication temperature reaches the upper limit of the temperature range, controller TC1 forms a control command with account of accepted law of control.

The general functional scheme of automation of the oiling cooling system is given in Fig. 4.

The structure of elements of the functional scheme is the following: disturbance-stimulated control block P1; twocircuit control block $\mathrm{P} 2$ on deviation of the process value; $\mathrm{C} 1$ - C3 elements-converters of output variables of temperature detectors S1 - S3 into physical quantities measured by them (to simplify presentation of the studied process peculiarities); actuator $\mathrm{M}$; final control element $\mathrm{R}$; separation unit of oil lubrication $\mathrm{N}$ into two flows: from the oil box through controlled object $\mathrm{CO}$ which is an element of the cooling system, i.e. the oil cooler, and into the oil box (bypassing the oil cooler).

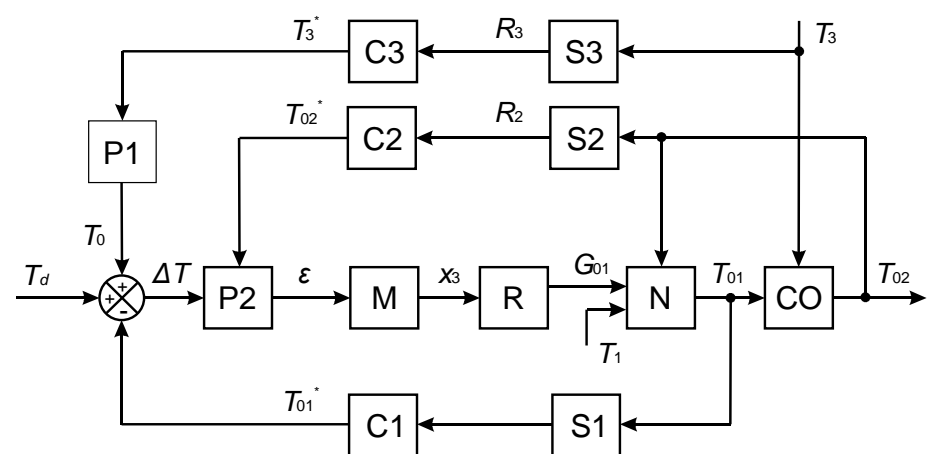

Fig. 4. The general functional scheme of oiling cooling system automation.

The notations of basic values of the functional scheme are the following: T3 - measured outer air temperature; T3* outer air temperature at the input to block P1; To - desired specified temperature of oil lubrication; Td - estimated temperature deviation of oil lubrication defined for the purpose of correction Tco; [delta]T - deviation on temperature of controlled variable T01; [epsilon] - adduced control signal of the regulator $\mathrm{P} 2 ; \mathrm{x} 3$ - reduced value of regulating unit movement; G01 - flow rate of oil lubrication after the final control element, i.e. before the separation unit of oiling; T01 oil lubrication temperature before the controlled object (T01 equals pump delivery temperature and oil box temperature (bypassing the oil cooler)); $01^{*}$ - measured temperature of oil lubrication; T02 - oil lubrication temperature after cooling; $\mathrm{T} 02 *$ - measured temperature of oil lubrication at the input in P2.

\section{RESULTS AND DISCUSSION}

Mathematical modelling of the automated oiling system with account of the functional scheme and regulator structures $\mathrm{P} 1$ and P2 by the example of controller ECL - 301 (to simplify the scheme in Fig. 4, their structures are not disclosed) is represented as a system of equations (1).

The system (1) includes the following equations: an equation of motion of temperature detectors $\mathrm{S} 1$ and S3; equations for regulators $\mathrm{P} 1$ and $\mathrm{P} 2$ (an equation for calculation of specified temperature of oil lubrication $\mathrm{T}_{\mathrm{o}}$; a constraint equation to determine temperature deviations [delta] T; a nonlinear equation of the regulator dead band; an equation of regulator P2 similarly to specialized controllers ECL Comfort (Danfoss, Denmark); a nonlinear equation of the restricted area; an equation of the actuator (is considered to be an integrator) [9]; an equation of the final control element relatively to output variable $\mathrm{G}_{01}$; a constraint equation for devices of oil separation $\mathrm{N}$; an equation of motion of the controlled object on the link «oil lubrication temperature $\mathrm{T}_{02}$ after the oil cooler - oil lubrication temperature $\mathrm{T}_{01}$ at the input in the object»; an equation of motion of temperature detector S2.

$$
\left\{\begin{array}{l}
\tau_{d 3} \frac{d T_{3}^{*}(t)}{d t}+T_{3}^{*}(t)=k_{d 3} T_{3}(t), \\
\tau_{d 1} \frac{d T_{01}^{*}(t)}{d t}+T_{01}^{*}(t)=k_{d 1} T_{01}(t), \\
T_{o}(t)=f_{1}\left(T_{3}^{*}\right), \\
\Delta T(t)=T_{o}(t)+T_{d}(t)-T_{01}^{*}(t), \\
x_{1}(\Delta T)=\left\{\begin{array}{l}
0,-X_{d} \leq \Delta T(t) \leq X_{d}, \\
k_{1} \Delta T(t),|\Delta T(t)|>X_{d},
\end{array}\right. \\
\varepsilon(t)=\frac{k_{m}}{X_{p}}\left[x_{1}(\Delta T) T_{u}+\frac{d x_{1}(\Delta T)}{d t}\right], \\
x_{2}(t)=\left\{\begin{array}{l}
k_{2} \varepsilon(t),-k_{m} \leq \varepsilon(t) \leq k_{m}, \\
k_{m},|\varepsilon(t)|>k_{m},
\end{array}\right. \\
\frac{d x_{3}(t)}{d t}=\frac{k_{u}}{\tau_{u}} x_{2}(t), \\
G_{01}(t)=G_{1} k_{k} e^{k_{2} x_{3}(t)}, \\
T_{1} G_{01}(t)+T_{02}(t)\left(G_{c o}-G_{01}(t)\right)=G_{c o} T_{01}(t), \\
\tau_{1} \tau_{2} \frac{d^{2} T_{02}(t)}{d t^{2}}+\left(\tau_{1}+\tau_{2}\right) \frac{d T_{02}(t)}{d t}+T_{02}(t)=k T_{01}(t), \\
\tau_{d 2} \frac{d T_{02}^{*}(t)}{d t}+T_{02}^{*}(t)=k_{d 2} T_{02}(t),
\end{array}\right.
$$

The additional notations in the system of equations (1) are as follows: $\mathrm{k}_{\mathrm{di}}$ - transmission factor of $\mathrm{i}$-temperature detector; $\mathrm{G}_{\mathrm{co}}$ - the flow rate of oil lubrication from the separation unit of oil flows to the oil box; $\mathrm{G}_{1}$ - rated flow at the input of final control element; $\mathrm{T}_{1}$ - oil lubrication temperature in the output of pump; $\mathrm{x}_{1}$ - output variable of nonlinear regulator dead band $\mathrm{P}_{2} ; \mathrm{x}_{2(\mathrm{t})}-$ output variable of nonlinear restricted area (saturation) in the regulator $\mathrm{P}_{2} ; \mathrm{k}_{1}$ and $\mathrm{k}_{2}$ - proportionality factors, correspondingly, of nonlinear dead bands and regulator restriction $\mathrm{P}_{2} ; \mathrm{X}_{\mathrm{d}}$ - regulator dead band $\mathrm{P}_{2} ; \mathrm{X}_{\mathrm{p}}-$ regulator proportionality factor $\mathrm{P}_{2} ; \mathrm{T}_{\mathrm{i}}-$ regulator constant $\mathrm{P}_{2}$.

On the basis of the mathematical modelling (the system of equations (1)), using simulation modelling in Simulink, the authors study the peculiarities of the functioning of the oiling cooling automation system (Fig. 3). To perform simulation 
modelling at the initial instant $\mathrm{t}=0$, let us assume that the temperature fall $\mathrm{T} 01$ is in progress by decreasing by $9^{\circ} \mathrm{C}$ (calculated deviation $\mathrm{Td}$ ). The duration of simulation in all cases is $7 \mathrm{~min}$.

Initial parameters for simulation modelling in Simulink for central oiling stations [10] are given in Table 1.

TABLE I.

INITIAL PARAMETERS OF SIMULATION MODELLING

\begin{tabular}{|l|c|}
\hline \multicolumn{1}{|c|}{ Parameter name, its notation } & $\begin{array}{c}\text { Value, } \\
\text { dimension }\end{array}$ \\
\hline Conversion coefficient of the controlled object, $k$ & 0.813 \\
\hline Time response of the controlled object, $[\mathrm{tau}]_{l}$ & $63.25 \mathrm{~s}$ \\
\hline Time response of the controlled object, $[\mathrm{tau}]_{2}$ & $42 \mathrm{~s}$ \\
\hline Initial temperature in the system, $T_{2}$ & $48.2^{\circ} \mathrm{C}$ \\
\hline Maximum flow at the input, $G_{1}$ & $16 \mathrm{~m}^{3} / \mathrm{h}$ \\
\hline Maximum flow in the system, $G_{o}$ & 14.7 \\
& $\mathrm{~m}^{3} / \mathrm{h}$ \\
\hline Outer air temperature, $T_{3}$ & $1.0{ }^{\circ} \mathrm{C}$ \\
\hline Starting position of valve stem M & $74.6 \%$ \\
\hline Regulator parameter $\mathrm{P} 2, k_{m}$ & $100 \%$ \\
\hline Regulator parameter $\mathrm{P} 2, X_{d}$ & $0{ }^{\circ} \mathrm{C}$ \\
\hline
\end{tabular}

Time response of temperature detectors [10] is given in Table 2.

TABLE II.

INITIAL PARAMETERS OF TEMPERATURE DETECTORS

\begin{tabular}{|l|l|c|}
\hline $\begin{array}{c}\text { Detector } \\
\text { type }\end{array}$ & \multicolumn{1}{|c|}{ Designation and notation } & $\begin{array}{c}\text { Value, } \\
\text { dimension }\end{array}$ \\
\hline $\begin{array}{l}\text { ESMU-100 } \\
\text { (D1 and }\end{array}$ & $\begin{array}{l}\text { Displacer-type detector of temperature } \\
\text { of oil lubrication in muff, [tau }]_{\mathrm{d} 1}\end{array}$ & $32 \mathrm{~s}$ \\
\hline 22) & $\begin{array}{l}\text { Temperature detector of outer air, } \\
{[\mathrm{tau}]_{\mathrm{d} 3}}\end{array}$ & $900 \mathrm{~s}$ \\
\hline ESMT (D3)
\end{tabular}
3.

Characteristics of regulatory valve PO are given in Table

TABLE III.

INITIAL PARAMETERS OF REGULATORY VALVE PO Parameter name, notation

\begin{tabular}{|c|c|}
\hline Parameter name, notation & Value, dimension \\
\hline Diameter, $D_{y}$ & $40 \mathrm{~mm}$ \\
\hline Coefficient, $k_{k v s}$ & $25 \mathrm{~m}^{3} / \mathrm{h}$ \\
\hline Temperature, $T_{\min }$ & $5^{\circ} \mathrm{C}$ \\
\hline Temperature, $T_{\max }$ & $150^{\circ} \mathrm{C}$ \\
\hline Valve rod travel, $h$ & $10 \mathrm{~mm}$ \\
\hline
\end{tabular}

Basic characteristics of actuator AME 20 of Danfoss [11] are given in Table 4.

TABLE IV.

CHARACTERISTICS OF ACTUATOR AME 20

\begin{tabular}{|c|c|}
\hline Parameter name & Value, dimension \\
\hline Voltage & $24 \mathrm{~B}$ \\
\hline Frequency & $50 / 60 \mathrm{~Hz}$ \\
\hline Working power & $4 \mathrm{~W}$ \\
\hline Control signal type & analogue \\
\hline Generating force & $450 \mathrm{~N}$ \\
\hline Valve rod travel & $10 \mathrm{~mm}$ \\
\hline Rod travel time on 1 mm & $15 \mathrm{~s} / \mathrm{mm}$ \\
\hline Input signal 1 & $0-10 \mathrm{~V} ; R_{i}=24 \mathrm{kOhm}$ \\
\hline Input signal 2 & $0-20 \mathrm{~mA} ; R_{i}=500 \mathrm{kOhm}$ \\
\hline Output signal & $0(2)-10 \mathrm{~B}$ \\
\hline Reset spring & No \\
\hline &
\end{tabular}

\begin{tabular}{|l|c|}
\hline Environment minimum temperature & $0{ }^{\circ} \mathrm{C}$ \\
\hline Environment maximum temperature & $55^{\circ} \mathrm{C}$ \\
\hline
\end{tabular}

The regulator equation P2 (2) (which, with account of the actuator in the form of integral, is the PI-controller) is:

$$
\varepsilon(t)=\frac{k_{m}}{X_{p}}\left[x_{1}(\Delta T) T_{u}+\frac{d x_{1}(\Delta T)}{d t}\right],
$$

where $X_{p}=60^{\circ} \mathrm{C}, T_{u}=12 \mathrm{~s}$.

The simulation results on the basis of the proposed mathematical model are shown in Fig. 5 - 7.
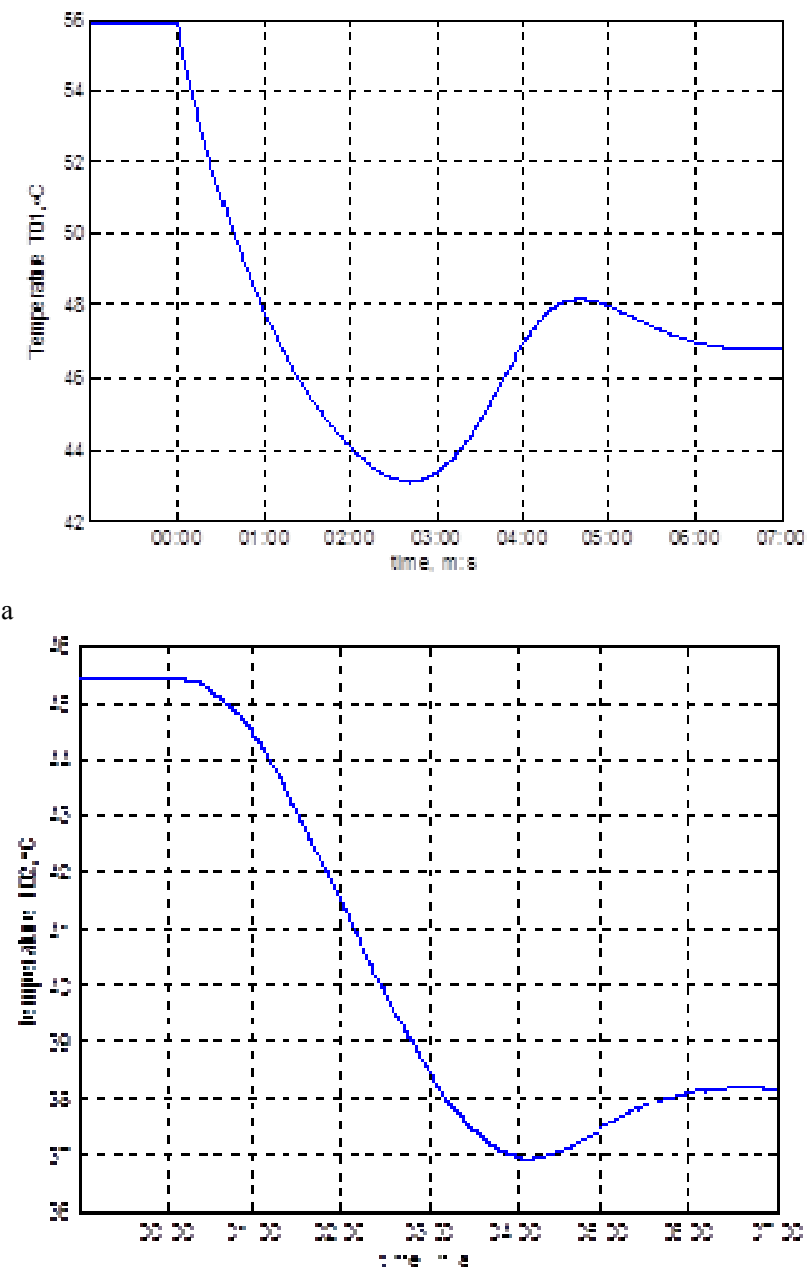

b

Fig. 5. Dependence of temperature change T01 at the input of the oil cooler (a) and temperature T02 after the oil cooler (b).

For this type of actuator, the studied characteristics of temperature T01 at the input of the oil cooler are shown in Fig. 5 a, and temperature T02 after the oil cooler - in Fig. 5 b. 


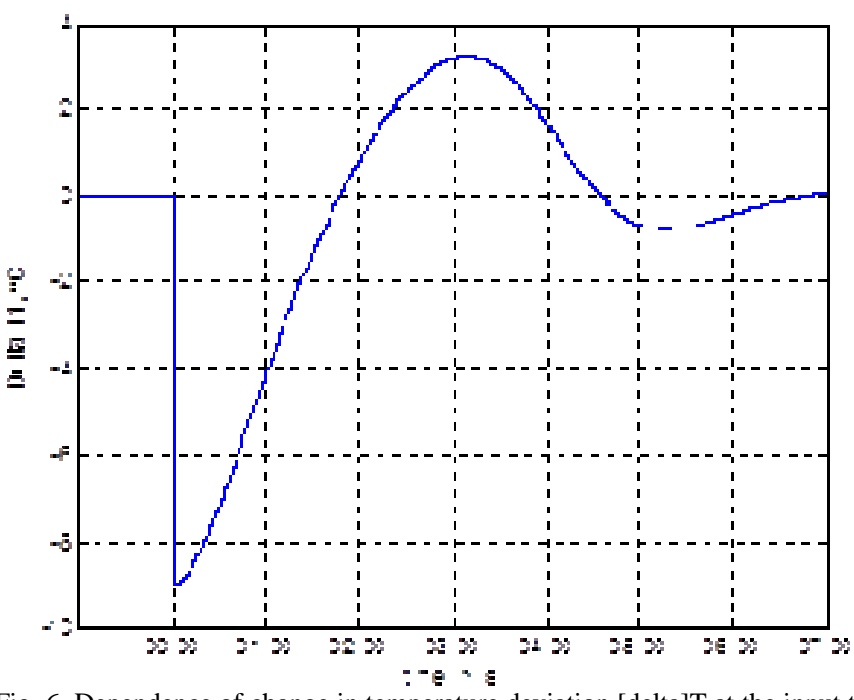

Fig. 6. Dependence of change in temperature deviation [delta] $\mathrm{T}$ at the input to regulator block $\mathrm{P} 2$.

The peculiarities of change in temperature deviation [delta]T from preset block $\mathrm{P} 2$ at the input to the regulator are shown in Fig. 6.

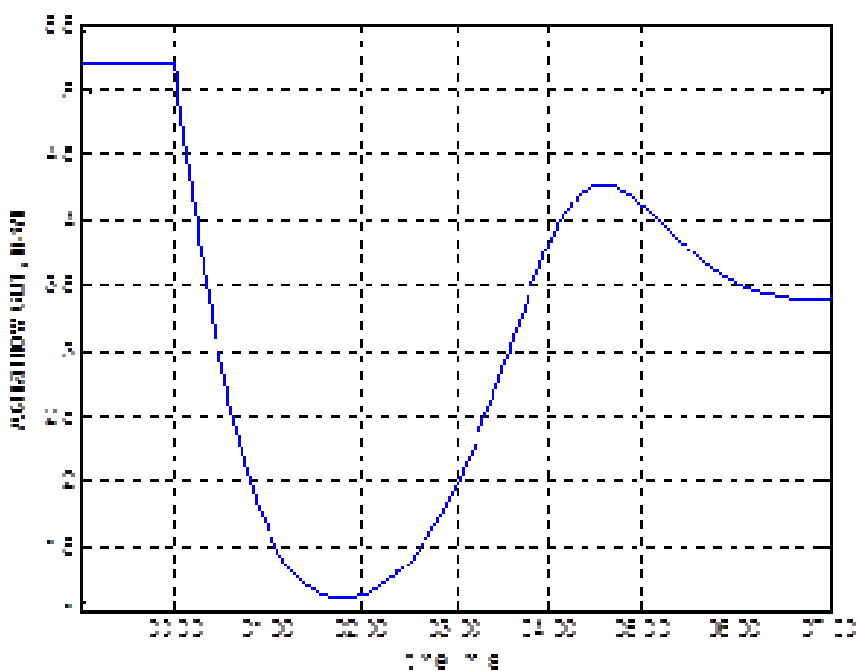

Fig. 7. Dependence of change of the flow rate at the input of coolant over time.

Dependence of flow rate change at the input of the oil cooler is shown in Fig. 7; moreover, the flow rate at the initial instant amounts to the value equal to $5.2 \mathrm{~m}^{3} / \mathrm{h}$.

\section{CONCLUSION}

Present-day automated control systems of central oiling stations have given new opportunities to develop «intelligent» systems of mill burden level measurement. The functioning of this measurement system is based on dependence of change of hydraulic pressure in low-pump on the load ratio, for example, of the autogenous grinding mill. For the functioning of «intelligent» systems of load ratio measurement, the peculiarities of the automated oiling cooling system for breaking pressure-temperature relationship are performed. Numerical calculations and simulation of functioning processes of the automated oiling system with account of cooling have shown peculiarities of the studied processes and efficiency of the proposed solution.

\section{Acknowledgment}

The work is realized within the framework of the Program of flagship university development on the basis of Belgorod State Technological University named after V.G. Shoukhov, with the use of equipment of the High Technology Center at BSTU named after V.G. Shoukhov.

\section{References}

[1] D.V. Medvedev, "Automatic oiling systems of open gear drives of the drum mill drive," in Bulletin of St-Peterburgh railway engineering university, 3, pp. 105-112, 2009.

[2] A.I. Gosman, "Cental oiling systems grinding mill machinery," The mining industry, 4, pp. 29-32, 2004.

[3] M.A. Zyabrev, M.I. Shupichenko and M.V. Polyanskiy, "Automated central oiling systems of mountain and concentrating machines," from Materials of scientific conference NPO «RIVS-2008», St-Petersburgh, 2008, pp. 49-51.

[4] A.E. Trop, B.Z. Kozin and E.V. Prokopjef, Automatic process control of dressing plants, Moscow: Publishing house Nedra, 1986, p. 303.

[5] N.B. Sibirtseva, A.N. Potapenko and A.N. Semernin, "Peculiaritities of automation ofraw mill charge as a component of automatic dispatch control systems," Bulletin of Samara scientific centre of the Russian Academy of Science, vol.13, №1(3), pp. 641-645, 2011.

[6] Boyer, A. Stuart, SCADA Supervisory Control and Data Acquisition, USA: ISA - International Society of Automation, 2010.

[7] G. Michael, "Forbes and Bill Gough. Model predictive control of sag mills and flotation circuits," Data Views 03.12.2015. http://www.andritz.com/de/aa-automation-mpc-sag-mills-flotationcircuits.pdf, 2015.

[8] N.B. Sibirtseva, A.N. Potapenko and N.A. Semiletov, "Measurement methods of mill charge level based on physical processes of modern central oiling systems", Bulletin of Samara scientific centre of the Russian Academy of Science, vol. 12, №4(3), pp. 694-697, 2010.

[9] A.N. Potapenko, Basics of process automation of building central heating system: textbook. Belgorod: BSTU named after V.G. Shukhov, 2006, p. 206.

[10] Automated central oiling systems. Product catalogue of LLC «Universal - Technics». Data views 2.12.2015. http://www.lincolnrusmoscow.ru/Text/catalog2.pdf.

[11] Product catalog of Danfoss group global. Date Views 02.12.2015 http://products.danfoss.ru/home/ 